\title{
"The Effectiveness of a Training Program of English Language Teachers' Questions in the Achievement of their Students and Developing their Thinking Skills"
}

\author{
Dr. Marwan Rashed Abd-EI Rahem Arafat
}

\section{SUMMARY}

The present study aimed at identifying the effectiveness of a training program in teacher questions on developing first-year secondary stage students' achievement and thinking skills. To achieve this objective the study utilizes a training program in teacher questions. Moreover, the researcher develops an achievement test in EFL and adopts a test for measuring the thinking skills of secondary stage students. The following research questions are to be answered:

1. Is there a difference between the subjects of the control and experimental groups in the scores of the achievement tests of the three subjects of the study? (Quantitative)

2. Is there a relationship between the type of questions the teacher asks and the level of thinking of the students? (Qualitative)

Subjects of the study will consist of 60 students who will be randomly chosen from among a larger population of Taif secondary stage students. They will be randomly and equally divided into two groups (an experimental group that will receive the training in the question types and a control one that will be instructed using the regular method of teaching. The study is expected to suggest some important results that will benefit EFL stakeholders. Also, a set of recommendations and suggestions for further research will be offered.

Key Words:

- Teacher Questions.

- Thinking skills.

- Achievement.

\section{Introduction}

Classroom questioning is a topic that has been exhaustively researched. A question is any sentence or utterance which has an interrogative form or function. In the classroom, teacher questions are defined as instructional cues or stimuli that convey to students the content elements to be learned and directions for what they are to do and how they are to do it. The types of questions teachers ask in the classroom play an 
essential role in the learning process and on learners' thinking. The high incidence of questioning as a teaching strategy used by teachers, and its consequent potential for influencing student learning and thinking, have led many researchers to investigate relationships between question types and student achievement and behavior. Research indicates that questioning is second only to lecturing in popularity as a teaching method and that classroom teachers spend anywhere from thirty-five to fifty percent of their instructional time conducting questioning sessions (Kathleen Cotton 1988).

Classroom questioning practice has been the focus of numerous education researchers for over 100 years. Although it is widely assumed that classroom questioning promotes student thinking and learning, research in actual classrooms indicates that current practice falls far short.

One of the most basic kinds of language used in the classroom is teacher questioning. Teachers are often encouraged to ask higher-level questions to improve their students' abilities, asking more "why" and "how" questions and fewer "what" and "when" questions. There is no evidence, however, that answering these kinds of questions alone has a direct effect on students' ability to think.

Wegerif (2002) illustrates this conclusion with the example of a teacher asking "Why did Huck Finn's father abduct him?" This question could elicit deep thinking and may help some students improve their thinking abilities but, as he explains, if students "are in the habit of guessing or making hasty judgments about what causes things to happen," they will just continue to practice patterns of shallow thinking.

Some, so-called deeper questions, ask students for subjective judgments: "What did you think of the poem?" "Should we clone human beings?" Students can usually 
answer such questions easily, but without having to justify and support their opinions, they are not likely to grow as thinkers (Appelbaum, 2000). In a thinking classroom, the teacher's response to a "why" or "how" question is "How do you get that?" "What reasons do you have?" "Where do your reasons come from?" "What about this other point of view?" These kinds of questions from a teacher and from students become part of the culture of a thoughtful classroom and ensure that there is more to answering a good question than a flippant, easy response.

Building classroom learning around good questions is an important part of encouraging thinking in students, but it is not sufficient. The questions must be accompanied by appropriate feedback, assessment, and instruction in how to think about them.

\section{Statement of the Problem:}

The main problem of this research is: What is the role of the questions that English teachers use in their classrooms in developing the thinking skills of secondary schools students in a public high school in Taif?

To answer this question, the following minor questions were devised:

1. Is there a relationship between the type of questions the teacher asks and the level of thinking of the students ?

2. Is there a difference between the subjects of the control and experimental groups in the scores of the achievement tests of the three subjects of the study?

\section{Aims of the Research:}

\section{The aims of the present study attempted to:}

1. Identify the relationship between the type of questions the teacher asks and the level of thinking of the students. 
2. Identify the difference between the subjects of the control and experimental groups in the scores of the achievement tests of the three subjects of the study.

\section{Specifically, the research aims at:}

- Looking at the important role that questions play in the language teaching process and to the kinds of questions that teachers use in their language classrooms.

- Raising awareness and encouraging teachers to ask their students not only low-level questions but also higherorder level questions.

- In the same token, training and encouraging students to think critically and be able to ask higher-order level questions.

\section{Definition of Terms:}

\section{Thinking Skills:}

Thinking skills are cognitive processes that enable us to make meaning from and create with information. Often included under the definition of thinking skills are habits of mind or thinking behaviors that define attitudes and dispositions of good thinkers. Researchers (i.e. Beyer, Marzano, Perkins, Costa, Feurerstein) believe that students can be taught specific meta-cognitive strategies for thinking skills that allow them to more effectively and efficiently process information. They can also learn to demonstrate habits of mind or thinking behaviors in their daily activities.

\section{Related Literature}

According to Paul, R. and Elder, L. 1996, the key to powerful thinking is powerful questioning. When we ask the right questions, we succeed as a thinker, for questions are the force that powers our thinking. Thinking, at any point in time, 
can go off in thousands of different directions, some of which, by the way, are dead-ends. Questions define the agenda of our thinking. They determine what information we seek. They lead us in one direction rather than another. They are, therefore, a crucial part of our thinking.

The ability to engage in careful, reflective thought is viewed in education as paramount. Teaching students to become skilled thinkers is a goal of education. Students must be able to acquire and process information since the world is changing so quickly. Some studies purport that students exhibit an insufficient level of skill in critical or creative thinking. In his review of research on critical thinking, Norris (1985) surmised that students' critical thinking abilities are not widespread. Most students do not score well on tests that measure ability to recognize assumptions, evaluate controversy, and scrutinize inferences.

Critical thinking is cited as an important issue in education today. Attention is focused on good thinking as an important element of life success (Huitt, 1998; Thomas and Smoot, 1994). "Perhaps most importantly in today's information age, thinking skills are viewed as crucial for educated persons to cope with a rapidly changing world. Many educators believe that specific knowledge will not be as important to tomorrow's workers and citizens as the ability to learn and make sense of new information" (Gough, 1991).

Thus, students' performances on measures of higherorder thinking ability reveal a critical need for students to develop the skills and attitudes of effective thinking. Furthermore, another reason that supports the need for thinking skills instruction is the fact that educators appear to be in general agreement that it is possible to increase students' creative and critical thinking capacities through instruction 
and practice. Presseisen (1986) asserts that the basic premise is students can learn to think better if schools teach them how to think. Adu-Febiri (2002) agrees that thinking can be learned. According to Sousa (2006), students are not actually taught to think because children are born with the brain organizational structure that originates thinking. As educators, students can be assisted in organizing the content of their thinking to facilitate complex reasoning. Sousa supports Bloom's Taxonomy as an organizational structure that is compatible with the manner in which the brain processes information to promote comprehension.

Hayes and Alvermann found that coaching teachers led to significant changes in students' discussion, including more critical analysis. The supervision model that was used allowed teachers and researchers meet for pre-observation conferences in order to set the purpose for the observation. Then, each teacher's lessons were videotaped and observers made field notes to supplement the videotape. After the lesson, the researchers met to analyze the tape and notes and to develop strategies for coaching the teachers. In another postobservation meeting, the teachers and supervisors planned future lessons incorporating the changes they felt necessary to promote and improve critical discussion in the classes.

Hayes and Alvermann report that this coaching led teachers to acknowledge students' remarks more frequently and to respond to the students more elaborately. It significantly increased the proportion of text-connected talk students used as support for their ideas and/or as cited sources of their 
information. In addition, students' talk became more inferential and analytical.

Research on the relationship between the cognitive level of teachers' questions and the achievement of their students has proved frustrating to many in the field of education, because it has not produced definitive results.

\section{Bibliography}

Adu-Febiri, F. (2002). Thinking skills in education: ideal and real academic cultures. CDTL Brief, 5, Singapore: National University of Singapore.

Facione, P. A. (2007). Critical thinking: What it is and why it counts. Retrieved January 2, 2008, from:

http://www.telacommunications.com/nutshell/cthinking7. htm

Gough, D. (1991). Thinking about thinking. Alexandria, VA: National Association of Elementary School Principals.

Hayes, David A., and Alvermann, Donna E. (1986). "Video assisted coaching of textbook discussion skills: Its impact on critical reading behavior." Paper presented at the annual meeting of the American Research Association, San Francisco: April 1986. 11pp. ED 271734

Huitt, W. (1998). Critical thinking: An overview. Educational Psychology Interactive. Valdosta, GA: Valdosta State University. Retrieved May 7, 2007 from, http://chiron.valdosta.edu/whuitt/col/cogsys/critthnk.html.

Norris, S.P. (1985). Synthesis of research on critical thinking. Educational Leadership, 42, 40-45.

Paul, R. and Elder, L. (May 1996). "The Critical Mind is A Questioning Mind" Foundation for Critical Thinking

Presseisen, B.Z. (1986). Critical Thinking and Thinking Skills: State of the Art Definitions and Practice in Public Schools. Paper presented at the Annual Meeting of the 
American Educational Research Association, San Francisco, CA.

Sousa, D. (2006). How the Brain Learns. Thousand Oaks, CA: Corwin Press.

Thomas, G., \& Smoot, G. (1994, February/March). Critical thinking: A vital work skill. Trust for Educational Leadership, 23, 34-38.

Wegerif, R. (2002). Literature review in thinking skills, technology, and learning. Bristol, England: NESTA, 2002.

www.nestafuturelab.org/research/reviews/ts01.htm*

In accordance with this problem and in an attempt to address this shortcoming and in response to answer the recommendations of studies, research and scientific conferences, this study came to answer the following main question:

How effective is a training program in classroom questions of English teachers in increasing their students' achievement and developing their students' thinking skills?

The following questions were branched from this question:

1. What is the role of English teachers' classroom questions in the achievement of their students and in developing their thinking skills of first year secondary school in Taif?

2. To what extent do first year secondary stage students master creative thinking skills?

3. To what extent do first year secondary stage students master creative reading skills utilizing creative reading skills?

4. What is the impact of classroom questions in the development of creative thinking skills among first grade secondary students? 
5. What is the impact of creative thinking skills on creative reading skills among first grade secondary students?

\section{Importance of the study:}

\section{The importance of the study stems from the following:}

1. This study presents a proposed program to increase students' achievement and developing their creative thinking skills as a result of the role that classroom questions play in the learning process.

2. That the development of thinking skills helps the learner to think well in the problems of everyday life.

3. Presenting studies in the field of thinking is one of the requirements of the third millennium; this study came as a response to these requirements that have been expressed in the Fourth Scientific Conference of the Egyptian Society for reading and knowledge which was entitled (the development of reading and thinking).

4. This study also came as a response to the recommendations of many studies and previous research in this area, including studies presented at the Twelfth Conference of the Egyptian Association for Curriculum and Methods of Teaching (Educational Curricula and the Development of Thinking).

\section{Objectives of the study:}

1 - Measuring the achievement and creative thinking skills of secondary stage students.

2 - Developing a proposed program to increase students' achievement and students' creative thinking skills among first grade secondary stage students. 
3 - Measuring the effectiveness of the program in increasing students' achievement and creative thinking skills.

4 - Identifying the impact of creative thinking skills on creative reading skills.

\section{Limitations of the Study:}

1 - Measuring student achievement of the study group in the academic content of the first unit (Oil). The measurement was limited to three levels of knowledge which are: remembering, comprehension, and application.

2 - The study is limited to the development of creative thinking skills (fluency, flexibility, originality (uniqueness), details).

3 -The study is limited to first grade secondary school male students in Taif.

4 - The proposed program was implemented in the second semester, the period between 29/1/1433 to 29/2/1433 H.

5- The sample of the study is limited to (40) first grade secondary stage students.

\section{Tools of the Study:}

1-An achievement test in the first unit (Oil) from the first grade secondary curriculum which was taught utilizing the cognitive thinking strategy.

2.A creative thinking test.

3.A creative reading test for the first secondary grade students.

4.A creative reading skills checklist to be used as a measure for correcting the comprehension topics.

\section{Research Methodology:}

The descriptive analytical method has been used in this study so as to be used in assigning the creative reading skills

\section{0}


and the experimental approach in implementing the program and developing their creative thinking skills.

\section{Related Studies: Creative Thinking \\ Definition of Creative Thinking:}

Sternberg (1988) defined creative thinking as the thinking that includes multi-stage processes which includes defining the problem, identifying the important aspects and arriving at a new way to solve this problem.

Allagany and Aljamal define creative thinking as a mental process that a student goes through in successive and sequential stages in order to produce new ideas that were not previously there during his or her profound interaction with the educational situations in the curriculum and takes place in a consistent and harmonious atmosphere among its components (Ahmed Allagany and Ali Aljamal 1996, 79).

Creative thinking is "an individual's ability to produce, which is characterized by utmost unrestraint intellectuality, flexibility, originality and the unusual associations such as the individual's response to a problem or to an exciting situation. Creative thinking is to think beyond the familiar or clear things which results in the addition of ideas and new solutions that lead to new production" (Kauthar Abdullah Rahim AlSharif, 2000, 96).

\section{Teaching Creative Thinking:}

De Bono (1982) says that everyone can improve his or her creativity if they could learn how to use their imagination in an innovative and an effective manner. He adds that, improving creativity is not restricted to outstanding students. To prove this, designers and authors of teaching thinking programs are not necessarily the best thinkers. Creativity is a matter of motivation and commitment to thinking as a mechanical skill and through which new valuable things are

\section{1}

Journal of Arabic Studies in Education \& Psychology(ASEP) 
achieved. Thus, an important part of creativity is due to the way of thinking.

\section{Skills of creative thinking:}

Williams proposed several basic dimensions of creativity which are:

1. Fluency: which is ability to produce as many as possible number of ideas or questions?

2. Flexibility: which is ability to produce as many as possible number of varied ideas and shift from specific type of thinking to another one.

3. Originality/genuineness: which is ability to think properly or relevant expression as well as ability to produce creative ideas more than the common ones.

4. Enrichment and details: Ability to add many details for an idea or certain product.

\section{Stages of creative thinking:}

1. Initiation stage: This is initiating the life of creator so as to achieve innovation.

2. Incubation stage: This is middle stage between initiation and mediation (thinking).

3. Meditation stage: This is characterized by immediate achievement of innovative solution.

4. Verification stage: This stage tries to verify the validity of something by testing it to show its correctness. (Ismael Abdul-Fatah, 2003, 14).

\section{Relationship between creative thinking and skills of creative reading:}

The relationship between language and idea is strong and can represent argumentative relationship that affects both of them. Language is a basic tool for building knowledge, concepts and ideas as well as an essential means for developing linguistic ability for individuals. The Roman 
spokesman Sheshrone stated this argumentative relationship as "that the individual cannot be eloquent or fluent when he speaks about a topic which he cannot understand i.e. the expressive language needs clear ideas and concepts, thus consideration of thinking is the basic priority for objective of language teaching as well as learning the various educational subjects (Fathi Younis, 2004, 18).

Language and thinking resemble each others in the fact that they require the same basic operation upon which they depend: ability for abstraction and development, formation of categories and groups which are abilities of using language and thinking in their higher levels. In fact, both language and thinking are single process. The German philosopher Kant wrote "that thinking is the psychological speech and Wellgeston emphasized that thinking is non verbal usage of language ( Fathi Younis , 2004 , 17).

Edward De Bono said that: it is a wrong idea to assume that the poor person in linguistic expression as necessarily poor in thinking, we need language so as to make the other see what we are thinking about. It is impossible to assess the thinking of the person who is not able to use the language in expressing his ideas and more often speech and fluency are disguised in thinking.

The ability to generate ideas and linking them in a coherent and logical way involves a degree of thinking skill, but this ability is only expressed in term of linking many ideas according to the rules of language. Most often thinking can be poor and that is due to the failure to develop thinking skill in a high level (Edward De Bono , 1989 , 45). We can notice from the above mentioned discussion that the language skill should be parallel to thinking skills in general and creative thinking in particular as language with it branches is considerably linked 
with creativity. A coherent and series article can show a linguistic skill, but it is not necessarily conductive to thinking skill. We have to see what can underlie the linguistic skill and develop thinking skill $\mathrm{k}$ we need both of them (Edward De Bono, 1989, 45).

Writing is one form of language, and whenever it can be perfect, it can be effective and fruitful. Writing is a type of linguistic pattern upon which ideas are represented, and these patterns show ideas and adjust them. The relationship between thinking and writing is direct one and they cannot exist in the absence of another.

Graver said "writing has a momentum called sound, which is a part of every skill of writing process. We should give the student an opportunity to write from this sound that comes from them, because this sound represents their thinking and imagination (Saied Al-Sayeh Humdan, 2003, 692).

Collins and Gentner think that writing process can be divided into two types: Production of ideas and text which requires the following skills: Setting of objective, planning, translation and reconsideration. The writer focuses on one of these skills and temporarily forgets the others during writing. This model focuses on the importance of ideas that are produced in the brain, as production of these ideas is considered as a basic step and essential requirement so that a text can be produced. It is worth to mention that writing is a sum of mental processes that take place in the brain before they are represented in a form of words in papers (Wafaa Tayba, 2005, 34).

\section{Previous studies:}

\section{Hussein Al-Nagar study (1994)}

This study aimed at determining the effectiveness of using court program on the dimensions of fluency and flexibility in 
teaching thinking. The finding revealed that there is effectiveness of court program in fluency and flexibility dimensions, where as it has not effectiveness on genuineness dimension for the experimental group.

\section{Rana Adnan Matar study (2000)}

The objective of this study is represented in reviewing the impact of program of thinking learning "the unlimited talents in developing creative abilities and self concept "for a sample of grade five elementary students in Jordan. The results of the research reveled that there are statistical differences for the experimental group in all dimensions of standard in developing creative abilities.

\section{Fares Salih Sedggi study (2000)}

The objective of this study is represented in conceptualizing the impact of critical reading on creative reading for grade ten elementary students in Jordan as compared with traditional method. The findings of the study showed that reading has an impact on developing creative reading for the students.

\section{Gais Al-Mugdadi study (2000)}

This study aimed at conceptualizing the impact of teaching critical thinking program in developing creative characteristic and self actualization for grade eleven students in Jordan. The findings reveled that there are statistical differences in favor of experimental group in developing creative characteristics and self actualization.

\section{Saeed Al-Sayeh Humdan study (2003)}

This study aimed at conceptualizing the effect of classroom question in teaching figurative language and developing creative thinking for high school students in Egypt. The findings of the study reveled that there is effectiveness of classroom questions in teaching figurative language, 
developing creative thinking as well as skills of creative writing for the students.

\section{Saeed Khalifa Abdul-Kareem study (2003)}

This study aimed at measuring the impact of classroom question in terms of collaborative learning on creativity especially for solving some environmental problems pertaining to students of science in the first year in Qatar. The results of the study reveled effectiveness of this method in solving environmental problems.

\section{Mariam Al-Ahmadi study (2006)}

This study aimed at constructing a proposed training program for teachers of Arabic language and its impact on developing critical and creative thinking for students in Saudi Arabia. The findings of the study revealed the effectiveness of this program in training teachers for developing the skills of critical and creative thinking.

\section{Foreign studies:}

\section{Allan study (1981)}

This study aimed at checking the impact of mobile educational program on developing the skill of creative thinking and creative self actualization for the students. The results showed that there are statistical differences in favor of experimental group on Torrance and self actualization tests.

\section{Kormek and Joseph study (1983)}

The objective of this study is represented in gauging the impact of testing scientific methods on creative thinking, personal evaluation and achievement for elementary students. Among the most important findings of the study was the fact that the experimental group was more efficient in fluency, flexibility and genuineness. 


\section{Albano study (1985)}

This study aimed at measuring the impact of training program on developing creative thinking for adults. The findings of the study reveled that the success of the training program in improvement of superficial and verbal form of creativity as well as revealing that the skills of fluency, flexibility and genuineness have improved for the experimental group.

\section{Holmes Ganalli study (1989)}

This study aimed at evaluating the effectiveness of educational program for teaching skills of thinking. Among the most important findings concluded from this study was the fact that the sample students were developed in the skills which have been modified and they are challenged to increase their levels of thinking so as to conceptualize newly creative concepts.

\section{Ronzolli study (1991)}

The objective of this study is represented in evaluating creative production for the program of gifted students. The results were positive and encouraging for evaluation of creative production.

\section{Hinnet study (1993)}

This study aimed at conceptualizing the effectiveness of Perod program of creative thinking on skills of fluency, flexibility and originality. The results were negative as there were not any statistical differences on creative thinking skills for fluency, flexibility and originality dimensions.

\section{Comment on the studies:}

Upon reviewing the previous studies, we can clearly notice that they used various methods and strategies in developing creative thinking. Some of the studies have used court program for Bono, while others used critical thinking 
and program of unlimited talents. Some of the studies integrated more than one strategy and designed a proposed program for developing creative thinking, while some others used classroom questions. Certain studies are exclusively concerned with evaluating skills without developing them. The majority of the studies focused on developing skills of the students, where other studies were concerned with training teachers on developing these skills for the students. There are some studies which used classroom questions in teaching certain subjects and measuring its impact on skills of creative thinking. There was an attempt to develop creative thinking through school subject such as Saeed Al-Sayeh and Saad Abdul-Kareem studies. Due to the scarcity of the studies that have focused on the impact of developing thinking on the language skills (according to the knowledge of the researcher), this study which attempts to measure the impact of teaching thinking on skills of creative reading, was conducted through training program in classroom question for teachers of English language, as De Bono and Paget theories have concluded that there is correlation between development of thinking and language development in terms of reciprocal relationship where they affect each others.

\section{Study procedures:}

\section{Achievement Test:}

The achievement test was prepared according to the following steps:

\section{Construction of achievement test:}

This test aims at measuring knowledge and skills related with the content of training program. The test was constructed according to set of skills and their components as well as literature, previous studies, general and specific objectives of the program and scientific content. 


\section{Objective of the test:}

The objective of this test is represented in measuring academic achievement for first grade high school students, which represent the study group for the scientific content for the first unit (oil). The measurement is confined to three cognitive levels: (Memorizing, Comprehension and Application) for the lesson (The ARAMCO Exhibit: the story of oil) through prior and post application of the test and the statistical manipulation of results.

\section{Table of test specifications:}

The researcher determined the relative weight for the contents of the program units by calculating the number of subsidiary topics for each unit, then assigning the number of objectives in the three cognitive levels (Memorizing, Comprehension and Application) according to Bloom's categorization of learning objectives, calculation of relative weight for each objective in each unit of the cognitive level and calculation of the relative weight of the objective of each unit for each cognitive level for the entire contents of the program.

The researcher concluded that the relative weight of learning objective as follows: (memorization level 17.5\%, comprehension level 5.5\% and application level 76.7\%).

\section{Formulation of the test statements:}

The statements of the test are formulated according to multiple choice bases with considerable number of statements as well as the four alternatives for each statement so that it can suit first grade high school students.

\section{Writing of test instructions:}

The researcher has written the test instructions before the test. He was particularly focused on making such instruction clear and easy in writing. The specimen for answers was 
presented in terms of two solved examples. The instructions also included how to correct the answer as well as extracting the percentages for the scores attained by the student.After presenting the test for the arbitrators, and modifying it according to their views, and checking its reliability, the test was valid for application on the test sample so that to check its consistency.

\section{Test reliability:}

The achievement test was presented with its specification table in its preliminary form for a group of experts involved in teaching English language so as to authenticate the reliability of the contents and statements and the degree of their correlation with the topics of the first unit (Oil) as well as the level intended to measure it. Based on this, some statements have been reformulated as well as alternative tests so as to increase clarity and replacing some alternative with others. The test become reliable as regard its contents.

\section{Experimentation of the text:}

The achievement test in its preliminary form was applied on a group of (22) first grade high school students in one of Taif's southern high schools so as to: Validate the clarity of meanings and test instructions:The instructions of the test were read for the students with answers method. It has been noticed that there were not any enquiries which indicates the clarity of instructions for the students.

\section{Calculation of test consistency:}

The test consistency was calculated by using Keyword and Richardson's equation formula (21) (Wireman \& Jurs, 1999) and it was equal to $(0.87)$ which indicates that it has a high degree of consistency .

\section{0}

Journal of Arabic Studies in Education \& Psychology(ASEP) 


\section{Determination of test time:}

It has become evident from the investigative experimentation for the test that the suitable time for the students to answer all questions is (40) minutes.

\section{The final form of the test:}

The statements of the test in its final form amounted to (40). Each statement with a correct answer by the student is allocated (one mark) or (zero) if the answer was incorrect. Thus, the final mark of the test is (40) and the minimum one is (zero).

\section{Preparing the creative thinking test:}

\section{A-Objective and dimension of the test:}

The test measures creative thinking skills for the students with its four dimensions: fluency, flexibility, originality (genuineness) and details. The test statements were distributed among these dimensions.

\section{$B$ - Test statements:}

Due to the lack of test in creative thinking in Arabic language that suits first year high school students as well as the objective of the study, we reviewed many tests and measurements in educational psychology references such as Douglas Holmes measurement for creative personality (2004) and A . Harrison, Primison, Berlet et al standard for thinking methods (2004) , Dr. Abraham test for creative thinking (2006). We also reviewed thee net standard for verbal creative thinking (1997) and the Jordanian version of Torrance standards for creative thinking ( Farouq Al- Roshan, 1999) so as to know how to measure creative abilities as well as the formulation of the question. The test statements were as follow:

1. First activity: Which measures fluency dimension and it consists of two questions each one includes twenty blanks.

\section{1}

Journal of Arabic Studies in Education \& Psychology(ASEP) 
2. Second activity: Which measures flexibility dimension and it consists of two questions each one includes twenty blanks.

3. Third activity: Which measures originality (uniqueness) dimension and it consists of two questions each of which includes twenty blanks.

4. Fourth activity: which measures details dimension and it consists of two questions each of which includes twenty blanks.

Therefore, the test includes a total of (160) blanks.

\section{Test reliability:}

The test reliability was checked by presenting it to a group of arbitrators and has been amended according to their suggestions.

\section{Test consistency:}

The test consistency has been calculated by suing Spearman and Brown equation for re test ( Al-Sayed, 1978 , 32). The consistency average was 0.85 which indicate that the test has a considerable degree of consistency.

\section{Test instructions:}

The study used Al-Safi's instructions (1997) for creative thinking test as these instructions suit the current study, the instruction were set at the beginning to the test.

\section{Correction of the test:}

A mark was allocated for each space that is filled with a correct and acceptable idea by the student, while the repeated gaps or the wrong ones are allocated zero. Therefore, the maximum degree is (160) which represents the quantitative estimation of the test. The qualitative estimation is carried out by allocation of right responses of the students and those 
answers which are repeated within $25 \%$ or less for the answers of the group members which are considered as creative answers and they are allocated (4) marks, and those which are repeated with $25 \%$ or less than $50 \%$ are allocated 3 marks, and those which are repeated with $50 \%$ and less than $75 \%$ are allocated two marks and finally those which are repeated with $75 \%$ and less than $100 \%$ are allocated one mark. The total of these marks is called qualitative or quantitative marks and thus the responses of the students are categorized into four creative levels and converted into percentiles.

\section{Proposed program and includes (annex No .........) \\ Objectives:}

The general objective of the training program in classroom questions for teachers of English language is represented in: developing achievement and creative thinking skills for first year high school students.

\section{From this objective, the following objectives stem:}

By the end of this program the student will be able to:

Produce as much as possible number of ideas, generate alternatives solve problems, study probabilities, change his style of thinking, think over alternatives, produce probabilities, does not imitate the ideas of those surrounding him, avoid similar ideas, presents good solutions, challenge problems, plan elongated planning, explain and elaborate.

\section{Content:}

The program includes introduction about definition of creativity, its motives through the classroom questions as well as methods of developing it. Then the classroom questions, rules of formulating and processing them, and the assisting factors for their success. After that, there are four lessons each of which is concerned with one skill of creative thinking through classroom questions. The class starts with giving brief

\section{3}

Journal of Arabic Studies in Education \& Psychology(ASEP) 
theoretical idea about the skill, then number of instructions that should be considered by the teacher upon teaching the skill, after that the teacher presents application activities, and through tackling these activities, the teacher uses classroom questions and trains the students on using this skill in a practical way.

\section{Teaching method:}

The current study used the classroom questions in teaching the proposed program as the previous studies and researches proved its effectiveness in developing the skills of creative thinking and achievement through classroom question. It is a type of mental strategies that can help in producing many varied ideas. In it, the students are asked to think over any idea, perception, information or memories that rotate on their minds as well as an relevant aspect of this idea or work that currently processed in their minds.

\section{Activities and relevant methods:}

\section{Activities:}

- Audio activities during the answer for classroom question and are represented in writing and recording ideas.

- Non verbal activities during the answer for classroom activities and are represented in participation of the students in term of providing ideas and discussing them.

\section{Methods:}

- Pictures and drawings used during the session.

- Big posters and white board markers (Flow master) to record ideas where all can see them.

\section{Methods of evaluation:}

Many evaluation methods have been used in this training program in classroom questions for teachers of English

\section{4}

Journal of Arabic Studies in Education \& Psychology(ASEP) 
language. These methods are represented in prior evaluation through applying the post test, progressive constructive evaluation, and personal evaluation during the application of the program and final assessment after application of the program.

After the completion of the program, it has been presented to arbitrators and adjusted according to their suggestions and become valid for application in its final form.

\section{Teacher's guide (Annex No .........)}

The teacher's guide includes introduction about the program, its objectives contents, method of teaching the program and detailed explanation for its procedures as well as questions and methods used and evaluation methods. The guide was presented to arbitrators and amended according to their suggestions until it arrives to its final form.

\section{A list of strategic skills in cognitive thinking: (annex No)}

After enumerating the strategic skills of cognitive thinking which should be available for first year high school students in terms of studies and researched that tackled skills of cognitive thinking, the list was presented for the arbitrators after showing correction method for each item so as to check the reliability and suitability of correction method, and amended according to their suggestions until it reached its final form, where the skills are divided into:

Eight basic skills which are: Concentration skill, information gathering skill, memorization skill, information organization skill, analysis skill, production skill, integration and combination skill, evaluation skill.

\section{-Test of creative reading: (Annex No .......)}

\section{A-Objective and dimensions of the test:}

This test measures skills of creative reading for first year high school students in terms of the four skills of creative 
thinking: fluency, flexibility, originality (uniqueness) and details through the test statements.

\section{B- Test statements:}

The test consists of four topics and the student has the free to choose two for the four tonics and write about them.

\section{C-Correction of the test:}

When correcting students' readings, the following criteria are used:

Skills are divided into two types: The first type includes: concentration, information gathering, and memorization and information organization skills. Each skill is allocated (10) marks, therefore the total marks of the skills of the first section are (40).

Second type includes: Analysis, production, integration and combination and evaluation skills. Each skill is allocated (10) marks, therefore the total scores of the second section skills is (40), and the maximum mark for the test of creative reading is (80).

- Form skills: Which are allocated (30) mark of the total score.

- Content skills: Which are allocated (70) marks of the total scores and the maximum test score is (100).

The reliability of the test was checked by presenting it to a group of arbitrators, and its consistency has been maintained by suing Spearman and Brown equation for the re test (Fouad Al-Bahi Al-Sayed, 1978 , 55), the consistency coefficient was $86 \%$ which is an acceptable percentage.

\section{Procedures of the study include:}

\section{Study sample:}

The researcher selected the experimental design on one group method in this research, where experiments are conducted on one group of individuals. The research sample 
included an experimental group from first year high school students totaling (40) students from (Taif High School) in Southern Taif Educational Administration in K.S.A.

\section{Prior and post application of achievement test :}

The achievement test was applied on the research experimental group so as to get the prior information that can help in statistical operations of the study results. It is revealed from the lack of statistical differences among averages of the cores in achievement test towards classroom questions which indicates the existence of harmony among the group members before applying the proposed training program in classroom questions for teachers of English language in developing thinking skills for the students.

After applying the achievement test in a prior form, the arithmetic means and standard deviations are calculated for the scores of the experimental group, as well as conducting the statistical analysis for the differences among average scores of research sample in prior application.

The researcher conducted the statistical analysis for the score of prior achievement test for the study sample and the results of the post achievement test.

The averages, standard deviations and $(\mathrm{F})$ value have been calculated by using ANOVA for the average scores of the students of experimental group which is 948 and 33 respectively.

There were statistically relevant differences on a level less than or equals 0.01 among the two averages modified for the students of the experimental group which studies according to the training program in the classroom questions for the teachers of English language - in the achievement test in favor of experimental group which has maximum average. 


\section{Duration of the program execution:}

The program took four weeks for it execution in terms of four hours per day, where each skill is taught within two hours.

\section{Prior application of creative thinking and creative reading tests:}

The two tests were applied on the student's sample of the research, and then the answer sheets were corrected and processed statistically.

\section{Practical steps for program execution:}

In the beginning, the researcher selected group of teachers and trained them on managing session of classroom questions so that each of them can be as a leader in its own group and familiarizing them with the required roles and how to manage the session as well as rules and principles that should be taken into consideration. Then the students were divided into groups each one comprises six students and a leader so as to manage the session besides a secretary to record the ideas. The student were familiarized with the objective of the program and the what is meant by creative thinking through classroom questions, skills and what is meant by classroom questions as regard their objectives, methodology and the rules that should be taken into consideration when performing the activity, encouraging students to use their thinking to a maximum level and utilizing it in serving the issue under discussion within the group that they work in. Then a lesson is taught each four hours in term of one hour for theoretical part and three hours for practicing activities.

\section{5- Post application of creative thinking skills:}

After completion of program execution and applying creative thinking test through classroom question on the sample of the student , it had been corrected by using (T) test ( Fauad Abu Hatab and Amal Sadiq k 1991 , 32) and the results are as follws: 
Table (1)

Results of differences between average scores of experimental group in creative thinking skills for students

\begin{tabular}{|c|c|c|c|c|c|c|c|}
\hline T & Mg F & MF & Mgm F & $\begin{array}{c}\text { Degree of } \\
\text { freedom }\end{array}$ & $\begin{array}{c}(\mathbf{T}) \\
\text { Value }\end{array}$ & $\begin{array}{c}\text { Table } \\
(\mathbf{T})\end{array}$ & $\begin{array}{c}\text { Level of } \\
\text { relevance }\end{array}$ \\
\hline 40 & 636 & 15,9 & 3430 & 39 & 2,71 & 10,74 & $\begin{array}{c}\text { Statistically } \\
\text { relevant on level } \\
1\end{array}$ \\
\hline
\end{tabular}

From the above table it is clear that there were statistical differences in favor of post application, hence the impact of classroom questions for the teacher of English on development of thinking skills is evident, also it indicates the effectiveness of the proposed training program for classroom questions for the teachers of English in developing thinking skills for the students . This result is consistent with the results of Al-Nagar study (1994), Rana Matar study (2000), Gaees Al-Mugdadi study (2000), Alan study ( 1981), Mormek study (1983) , Al-Bano study (1991), Hennit study (1993), Sayed AlSayeh Humdan study (2003) and Saeed Khalifa Abdul-Kareem study (2003).

That was the quantitative estimation of creative thinking skills through classroom questions for the students . As far as the qualitative estimation that shows the originality of the ideas forwarded by the students it is shown in this table.

Table (2)

Qualitative estimation that shows the uniqueness of ideas for the students.

\begin{tabular}{|l|l|l|}
\hline Level & Standard & $\begin{array}{l}\text { Percentage of student answers } \\
\text { in this level }\end{array}$ \\
\hline First & Less than 25\% & $10 \%$ \\
\hline Second & Less than 50\% & $\mathbf{1 5 \%}$ \\
\hline Third & Less than 75\% & $\mathbf{2 4 \%}$ \\
\hline Fourth & Less than 100\% & $\mathbf{5 1 \%}$ \\
\hline
\end{tabular}

The above table shows that the answers of the students in the first level is $10 \%$, the second level $15 \%$, the third level $24 \%$ and the fourth level is $51 \%$ and this indicates that there is a good percentage in the 
first and second levels that can reach $25 \%$, where as the percentage of the third and fourth level is superior due to the impact of intensive classroom questions on students. This result is consistent with the result of Sayed Al-Sayeh Humadan's study (2003).

\section{Calculation of the program effectiveness:}

Modified gain equation for Black (Hundam, 1984 , 225) was used to calculate and authenticate the effectiveness of the proposed program in terms of comparing the average degrees of prior test with that of the post test, and they amounted to $(1,8)$ which indicates the effectiveness of the proposed training program in classroom questions for the teachers of English in increasing the achievement of their students and developing their thinking skills.

Thus, the study have answered the first question through application of the prior test results as it shows the decrease in the level of creative thinking skills for the students, as well as answering the third question through prior application results as shown in the table where there considerable increase for the average marks.

\section{For answering the second and the fourth questions:}

2- What is the degree of the first grade high school student in mastering creative thinking skills?

4-What is the impact of developing creative thinking skills on creative reading skills for first grade high school students?

The test of prior creative reading was done so as the control the level of creative reading for the students under the study. Also, the test was applied after developing creative thinking skills through the proposed program by using classroom questions so as the measure the impact of developing creative thinking skills on creative reading skills. The averages of prior and post application as well as standard deviation were calculated so as to measure the change occurred before and after the application of program on form and content skills as it shown in able No (3). 
Table (3)

Table shows arithmetical secondary and standard deviations for students prior and post marks of students in creative reading skills

\begin{tabular}{|c|c|c|c|c|}
\hline Clerical skills & \multicolumn{2}{|c|}{ Prior application } & \multicolumn{2}{c|}{ Post application } \\
\cline { 2 - 5 } & $\begin{array}{c}\text { Arithmetic } \\
\text { secondary (3) }\end{array}$ & $\begin{array}{c}\text { Standard } \\
\text { deviation (4) }\end{array}$ & $\begin{array}{c}\text { Arithmetic } \\
\text { secondary (3) }\end{array}$ & $\begin{array}{c}\text { Standard } \\
\text { deviation (4) }\end{array}$ \\
\hline First section & $\mathbf{3 2 , 8 4}$ & $\mathbf{9 , 3 8}$ & $\mathbf{3 9 , 6 0}$ & $\mathbf{7 , 2 6}$ \\
\hline Second section & $\mathbf{8 2 , 3 6}$ & $\mathbf{1 5 , 3 7}$ & $\mathbf{9 9 , 8 3}$ & $\mathbf{1 0 , 8 0}$ \\
& & & & \multicolumn{2}{|c}{} \\
\hline
\end{tabular}

The above table shows the differences in the degrees of prior and post application, where there is decrease in the standard of the students in the prior application, as well as showing the improvement that occurred in the post application. The table further shows the improvement in the skills of the first section is less than that improvement that occurred in the skills of the second section which indicates that the program had focused on developing creative thinking.

" $T$ " test was used to measure the impact of the program on developing creative reading skills and results were presented as follows:

Table (4)

Shows the results of differences among prior and post average marks of experimental group for creative reading skills

\begin{tabular}{|c|c|c|c|c|c|c|c|}
\hline T & Mg F & MF & Mgm F & $\begin{array}{c}\text { Degree of } \\
\text { freedom }\end{array}$ & $\begin{array}{c}(\mathbf{T}) \\
\text { Value }\end{array}$ & $\begin{array}{c}\text { Table } \\
(\mathbf{T})\end{array}$ & Level of relevance \\
\hline 40 & 429 & 10,75 & 2993 & 39 & 2,71 & 7,73 & $\begin{array}{c}\text { Statistically } \\
\text { relevant on level } \\
0.01\end{array}$ \\
\hline
\end{tabular}

As the above table shows , there are statistical differences among the results of the prior application and that of [post application in favor of post application, where as the calculated $(\mathrm{T})$ is more that table $(\mathrm{T})$ and this indicates the superiority of the group in the post application . Thus, the study has answered the fourth question concerned with the impact of developing creative thinking skills on creative reading. The 
program developed the skills of fluency, flexibility and originality (genuiness) as well as ability to add details, thus enriched the students ideas and that was evident in the results of the post test for creative reading. This result is consistent with the results of Fares Salih Seddgi study (2004) and Sayed Hamdan Al-Sayeh study (2003).

\section{Discussion of Results:}

-The results of the study proved the effectiveness of the classroom questions in increasing students' achievement and the development of creative thinking skills. This is due to the fact that classroom questions motivate students' use of their utmost ability to think creatively. The intensive classroom questions sessions also helped to generate a large amount of ideas and the postponement of the drafting until the end of the session made the process of reading go through the natural stages. This means to say that generating the ideas and then drafting them carefully and deliberately was reflected in the creativity of the ideas that have been produced on students' creative reading skills.

- In classifying student responses in terms of how to determine the originality of students' ideas, four levels of creative responses have been developed: in the first level was the answer which was repeated by $25 \%$ and less; and $50 \%$ and less in the second; and $75 \%$ and less in the third; and $100 \%$ and less in the fourth level. It has been observed in classifying the answers that creative ideas were at the first level by $10 \%$ and $15 \%$ second level, $24 \%$ third level and $51 \%$.fourth level.

- The superiority of the third and fourth levels (24\% and 51\%) over the first and second levels may be due to students' influence by the ideas that were discussed at the classroom questions sessions where similar questions were discussed. 
- The issue of creative thinking and classroom questions raised students' motivation for learning because it removed the gap between the students and the teacher. It also freed the students from the constraints felt in the session wherein freedom of discussion and debate within the groups is encouraged. In addition, the issue of creative thinking is a new topic for students as it helps the student to discover his or her potentials.

- The cooperative learning method, which was used in the classroom s questions sessions, had a significant impact on the development of creative thinking which gave students the opportunity to exchange and modify ideas. It also increased the students' linguistic repertoire throughout getting affected by each other which in turn was reflected on the creative reading skills.

- The Pre-test for creative reading revealed students' weakness in creative reading skills, particularly in the creative skills (concentrating, information gathering, remembering, and organizing information).

- The following skills: (analysis, production, integration and consolidation, evaluation) have developed significantly more than the skills of (concentrating, information gathering, remembering, organizing information). This may be due to the following reasons:

1-The skills of (focusing, information gathering, remembering, organizing information) depend to an extent on what the student has learned in the past years. In addition, these skills need a long time to be developed.

2-Students' negligence of the skills of (concentrating, information gathering, remembering, organizing information) while focusing on ideas. 
3 - Since the training program in the classroom questions of English language teachers focuses on the development of creative thinking skills, this made the student focus on the idea more than the drafting.

\section{Recommendations:}

1. Care should be given to teaching creative thinking skills whether through separate course or within the education courses.

2. The dire need to training courses for teachers in modern methods and strategies in teaching since the traditional teaching methods are still dominant these days.

3. Classroom questions should be used in teaching specifically English language courses and the other subjects in general due to the effectiveness of this method and due to the emphasis to its effectiveness by other previous research studies.

\section{Suggested Research:}

- Using classroom questions in teaching literary texts and their impact on creative writing.

- The effect of classroom questions on teaching writing comprehension.

- Using classroom questions in teaching the language skills: reading, writing, listening and speaking and their impact on creative reading.

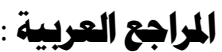

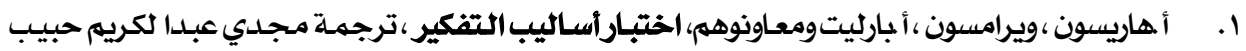

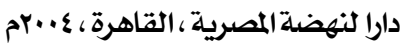

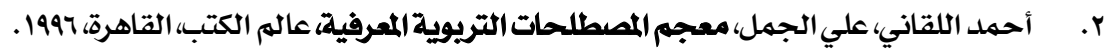

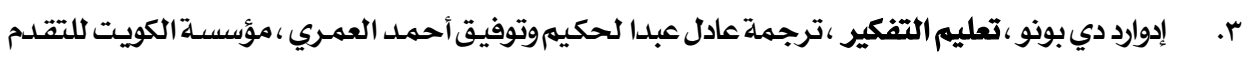

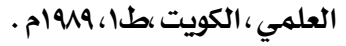

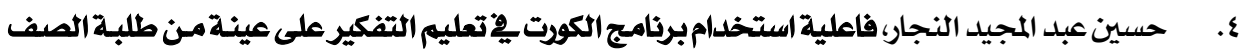

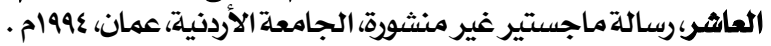

\section{4}

Journal of Arabic Studies in Education \& Psychology(ASEP) 


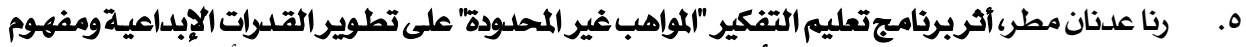

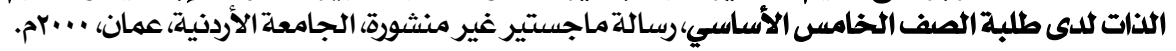

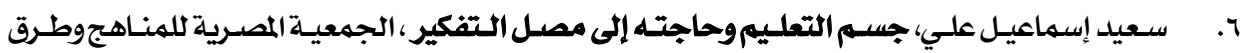

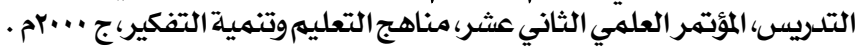

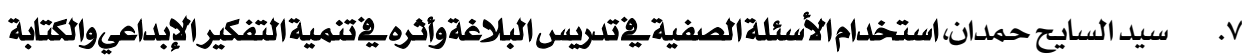

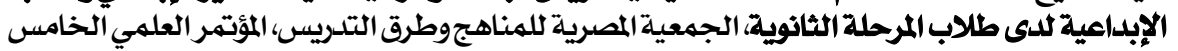

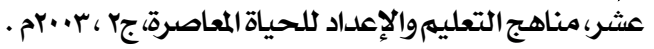

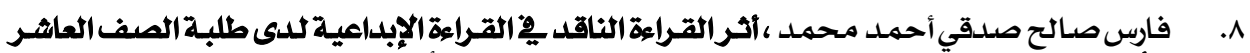

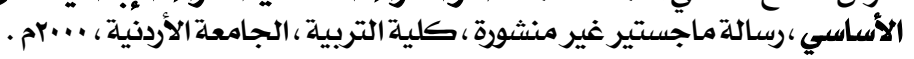

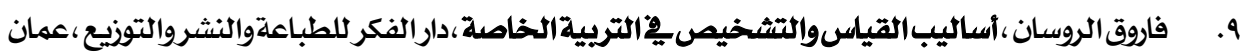

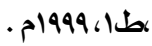

• ا. فتحي علي يونس ، أفكار حول القراءةوتنمية التفكير ، الجمعية المصرية للقـراءةوالمعرفة ، المؤتمر العلمي

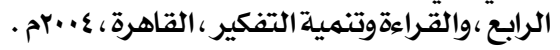

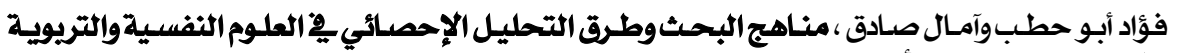
.11

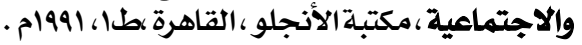

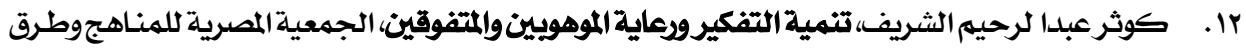

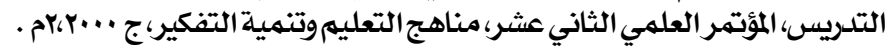

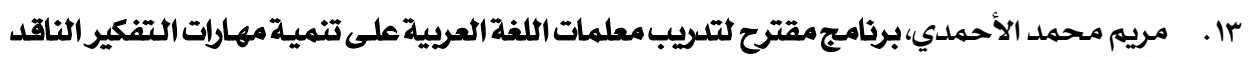

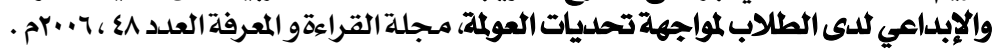

ع ا. مريم محمد الأحمدي، برثامجمقترح لتتمية مهارات الاتصال اللغوي الشفهي للدى طلاب كلية التربية

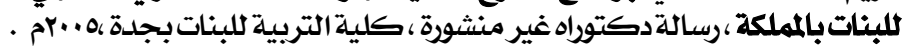

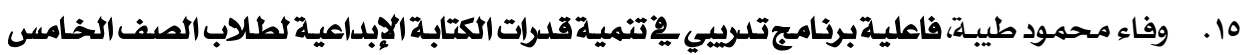

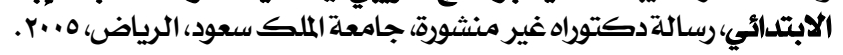

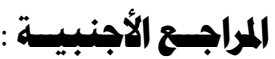

1. Amabil, Charles,1984. The effects of an experimental training Program on the Creative Thinking Abilities of Adults. Dissertation Abstracts International. Vol. 46, No. 19, pp. 809.

2. Collins, Allan and Gentner, Dedve, A Frame work for a Cognitive Theory of writing, In Gregg Wlee and Steinberg R Erwin (eds) Cognitive processes in writing, Lawrence Erlbum Associates,Inc,NJ.1980.

3. Wiersma \& Jurs,1999." The Effect of Selected teaching " Methods on Creative Thinking Self- evaluation and achievement of students enrolled in an elementary science education methods courses " Colorado State College.

4. Sternberg, R (ed), The Nature Of Creativity London, Cambridge university press, 1988.

溇潾潾潾潘 